\title{
0510 UNINTENTIONAL FIRES CAUSED BY PRODUCTS THAT FOCUS SUNLIGHT
}

B Altkorn, G Emerson*, X Chen, S Milkovich, D Stool Correspondence: Intertek, Phoenix Yard 69 King's Cross Road, London WC1X 9LN, UK

10.1136/ip.2010.029215.510

Unintentional Fires Caused by Products that Focus Sunlight Objectives The ability of myriad and sundry transparent and reflective objects to set fires by focusing sunlight has likely known since before the dawn of recorded history and was cited nearly 2500 years ago by Aristophanes. Yet modern generations greet this phenomenon with awe and bewilderment. Over the past decade product recalls, news stories and lawsuits have focused concern on domestic and wildfires set by such seemingly diverse objects as balls, garden ornaments, water bottles, dog bowls and lucky charms. No published safety standards or guidelines so much as mention this rara avis. We address it from historical and engineering perspectives and provide guidance on its assessment. Materials and Methods Recalled and historical products are reviewed. Fire prevention standards and literature involving radiant ignition are examined, as are terrestrial solar irradiance data. Relevant information from imaging and non-imaging optics is cited. Heat transfer variations between large and small irradiated areas are explained. Results of experiments with consumer products are presented.

Results Methods of recognising, assessing and minimising hazards of accidental fires from sunlight focused by transparent and reflected objects are discussed.

Discussion Understanding the radiometric characteristics of sunlight and focusing properties of transparent and reflective consumer products enables product designers to avoid unintentional fires. 